\title{
El reasentamiento en contexto minero. Entre la sugestión y la imposición de un nuevo orden
}

\author{
Bruno Hervé Huamaní*
}

* Candidato a doctor en Antropología para la Escuela de Altos Estudios en Ciencias Sociales de París (EHESS; CERMA - Mondes Américains). Actualmente, se desempeña como profesor (TPA) de sociología y antropología en la Universidad de París X Nanterre y como tutor en Pôle Paris Alternance Business School. Correo electrónico: bh.herve@gmail.com

Fecha de recepción: 24/04/18. Fecha de aceptación: 14/01/19 


\section{El reasentamiento en contexto minero. Entre la sugestión y la imposición de un nuevo orden}

\section{Resumen}

Para las instituciones que emiten las normas que los regulan (International Financial Corporation IFC y Banco Mundial - BM) y para las entidades que los realizan, en teoría los reasentamientos de población deben ser realizados solo cuando son «necesarios». Sin embargo, las experiencias muestran muy a menudo que lo necesario de un proyecto no tiene el mismo significado para sus promotores y para sus futuros vecinos. El argumento de la necesidad política de realizar los proyectos mineros diluye casi instantáneamente las alternativas eventuales para la población que sería desplazada.

Esta situación revela el poder que se atribuye a una empresa minera que, siendo promotora de un proyecto minero, se vuelve la gestora del futuro de una comunidad y, para ello, también de su presente. A partir de un caso peruano contemporáneo, desde un enfoque amplio, queremos mostrar el reasentamiento como un proceso complejo de gobierno «minero» en un contexto rural. Nuestra hipótesis es que un proyecto minero construye, en el territorio donde se instala, un nuevo orden social. A partir de un caso del sur peruano tratamos de mostrar en este trabajo de manera pragmática las asimetrías de recursos y de poder entre una empresa minera y una comunidad campesina.

Palabras clave: reasentamiento; gestión de población; poder; temporalidades; Perú.

\section{Population resettlement in a mining context. Suggestion and imposition of a new order}

\section{Abstract}

According to the institutions (the International Financial Corporation - IFC and World Bank - WB) that regulate population resettlement and are in charge of issuing population resettlement standards, and, according to the entities that enforce these regulations, in theory, resettlements have to take place only when they are "necessary". However, several cases has shown that what is necessary for mining projects developers differs from what is really necessary for their future neighbours - the population to be resettled. The argument of the political necessity of carrying out mining projects, almost instantaneously, annihilates any alternatives for a population to-be-displaced.

This situation has revealed true power that is attributed to a mining company. By implementing a mining project, a mining company becomes the manager of the future of a community, hence of its present.

Within the scope of this thesis we aimed to present the resettlement as a complex process of a "mining" government in rural context by using a broad approach applied to a Peruvian contemporary case.

Our hypothesis is that a mining project builds a new social order on a territory where it settles in. Based on a case from Southern Peru, we have attempted to demonstrate in a pragmatic way the asymmetries of resources and power between a mining company and a peasant community.

Keywords: Resettlement; population management; power; temporalities; Peru. 


\section{INTRODUCCIÓN}

El reasentamiento ${ }^{1}$ es un acto político que afecta a las personas involucradas en las dimensiones más cotidianas de la vida. El lugar propio (casa, territorio, país, etc.) tiene una importancia fundamental en la construcción de una «seguridad ontológica» (Margier, 2016). Por ello, un reasentamiento involuntario — visto como el cambio impuesto o sugerido de «lugar propio» por un Estado o una empresa- es un hecho muy singular. De manera general, un reasentamiento se aprecia a través de su dimensión física y mecánica. Se conoce la distancia que separa la nueva ciudad de la antigua, las dimensiones de ambos territorios, la cantidad de población por reasentar, como también el contenido de ciertas compensaciones básicas. Estos son elementos que ilustran la cara política la más visible de un reasentamiento. Pero otras dimensiones que deben tomarse en cuenta, como el tiempo, las interacciones sociales, la espera, las influencias, o las proyecciones imaginadas, son elementos que no se pueden medir a priori.

A partir del reasentamiento contemporáneo de una comunidad campesina por una empresa minera en los Andes del sur peruano, queremos proponer una mirada a largo plazo del proceso de reasentamiento. Usando documentos institucionales, legislativos y de varios trabajos etnográficos in situ, mostramos los elementos que hacen de un reasentamiento en contexto minero una operación política privada de gestión a largo plazo del territorio y de la población.

Para ello, nuestra propuesta se divide en tres partes que presentan el reasentamiento como una operación compleja. En primer lugar, trataremos de caracterizar el proceso de reasentamiento desde un punto de vista institucional y empresarial, pero también desde las percepciones locales. Luego trataremos de mostrar a través de qué elementos la empresa minera ejerce un poder político en la preparación del reasentamiento. Finalmente, la tercera parte propone un cuestionamiento crítico de la situación posterior al reasentamiento mediante previsiones institucionales previas y de observaciones recientes.

\section{CaRACTERIZACIÓN DE UN PROCESO CRÍTICO}

\section{Caracterizando el reasentamiento}

Los reasentamientos voluntarios e involuntarios son procesos sociales y políticos históricos. Musset (2002) muestra con abundantes ejemplos de qué manera la ciudad americana se construyó y reconstruyó a través del tiempo, de aconte-

\footnotetext{
1 Los diferentes actores citados para este trabajo usan reasentamiento y reubicación como sinónimos. Por razones de homogeneización del texto, hablaremos exclusivamente de reasentamiento, dejando sin embargo la palabra reubicación en las citas que así lo evocan.
} 
cimientos climatológicos, de guerras o de voluntades políticas. Desde la década de 1980, los reasentamientos de población son regulados por estándares internacionales establecidos por el Banco Mundial $(\mathrm{BM})^{2}$. Con el tiempo, esta base de estándares sugeridos para los proyectos públicos que el BM financiaba fue adoptada para grandes proyectos privados (Szablowski, 2002, p. 249).

Existen, según la clasificación del BM, cinco tipologías de reasentamientos forzados $^{3}$ : (i) desplazamiento por desarrollo; (ii) desplazamiento por guerra o guerra civil; (iii) desplazamiento por persecución étnica o religiosa; (iv) desplazamiento por desastres naturales, y (v) desplazamiento por transformaciones fronterizas (Sebenius et al., 2005, p. 239). Entendemos por «involuntarios» los tipos de reasentamientos que no son, desde un principio, el proyecto de la población afectada sino el de alguna entidad que, por su poder, tiene la facultad de proponer, imponer y realizar un reasentamiento. Según el Centro Financiero Internacional —entidad del Banco Mundial que emite las recomendaciones - el reasentamiento «[...] es involuntario cuando se produce sin el consentimiento fundado de las personas desplazadas o si estas otorgan su consentimiento sin tener la posibilidad de negarse al reasentamiento» (CFI, 2002, p. xi).

En el Perú, en contextos de grandes proyectos, por ejemplo, la servidumbre sugiere que la entidad promotora de un proyecto llegue a un acuerdo con la población por desalojar. Pero sugiere también que, en caso que no se encuentre un acuerdo, podrá aplicarse una serie de medidas legales, jurídicas o de fuerza para conseguir el desalojo ${ }^{4}$. Como indican Szablowski (2002, p. 259) y otros, si bien el desalojo "a la fuerza» no fue aplicado muchas veces por haber originado fuertes conflictos, la servidumbre siguió siendo evocada como un medio de presión para que los habitantes cedan sus tierras a las operaciones mineras.

2 OD 4.30 - Directriz Operacional del Grupo del Banco Mundial sobre reasentamiento involuntario. La OD 4.30 consagra los principios básicos y los procedimientos en que se funda el planteamiento de la CFI relativo al reasentamiento involuntario vinculado con sus proyectos de inversión.

3 Se habla de reasentamientos forzados para hacer explícito el carácter inicialmente no voluntario del reasentamiento. En este caso, la idea inicial o la «necesidad» de reasentamiento es evocada por entidades privadas o por el Estado. Al contrario, los reasentamientos voluntarios son los que fueron decididos por la misma población por razones de riesgos sanitarios, naturales, o de conflictos armados. 4 «La servidumbre minera también nace por mandato administrativo, atendiendo a la necesidad de explotar los recursos naturales que son de propiedad del Estado (artículo 66 de la Constitución) y que este cede a los particulares a través de la concesión minera. La ley prevé que, si el concesionario necesita usar un bien ajeno para explotar el derecho minero, se le puede imponer una servidumbre al propietario del predio necesario. Para este fin, se ha previsto un procedimiento administrativo que solo se inicia luego de agotadas las tratativas directas entre el concesionario y titular del predio que se quiere afectar. En el procedimiento administrativo se realizan pericias sobre la pertinencia de la servidumbre y sobre el valor de la compensación que el concesionario deberá pagar al propietario afectado. Si todo resulta favorable para el minero, finalmente se expide la resolución suprema que concede la servidumbre forzosa» (Mejorada, 2003, pp. 17-18). 
Al contrario de una migración que implica una iniciativa personal, la reubicación tiene una dimensión impuesta. Pero a pesar del carácter impositivo del reasentamiento involuntario, el CFI recomienda a los promotores de los proyectos de reasentamiento involuntario que aseguren «el mejoramiento de los medios de subsistencia y los niveles de vida que las personas afectadas tenían antes de su desplazamiento» (CFI, 2002, pp. 2-3).

Siguiendo esta tipología institucionalizada de reasentamientos, el desarrollo se puede entender como una razón análoga a las demás razones de reasentamiento. Esto quiere decir que el desarrollo (y sus proyectos) llegan a aparecer como una amenaza casi vital para las poblaciones beneficiadas por aquellos procesos. Siguiendo nuestro razonamiento, el desarrollo — y, por ende, el imaginario de modernidad-, viene a ser un riesgo imprevisible suficientemente «fuerte» para que las personas tengan que ser, literalmente, evacuadas. Desde un punto de vista moral, deducimos que los proyectos de desarrollo son —o en todo caso, pueden ser- potenciadores de precariedad, por lo menos para ciertas categorías de personas.

En el transcurso de los años 2000, entre diez y quince millones de personas fueron desplazadas cada año en el mundo por razones climatológicas, conflictivas, políticas o por proyectos de desarrollo (Sebenius et al., 2005, p. 232). Al igual que las demás causas críticas (guerras, catástrofes naturales, razones sanitarias, etc.), el desarrollo, tal como es calificado por el Banco Mundial, representa una causa suficiente y legítima de desplazamiento poblacional. Es decir, como una dinámica que fuerza u obliga a las personas implicadas a una eventualidad no negociable.

\section{El reasentamiento: una situación intrínsecamente crítica}

El reasentamiento es, entonces, un proceso crítico multidimensional, como veremos a lo largo del texto: abre una situación ineluctable, dejando incertidumbres para el futuro y aportando múltiples transformaciones (demografía, conflictos, etc.). El reasentamiento implica una logística previa de inventario. La entidad que lo maneja debe determinar todos los aspectos de «la vida» que deben ser tomados en cuenta para el proceso de reasentamiento. Esta es una tarea muy compleja que implica hacer el inventario de lo material (casas, terrenos, bienes, animales, etc.) y hasta cierto punto de lo inmaterial (ambiente, temperatura, referencias topográficas, etc.). El proceso es complejo, aun cuando implica reasentamientos voluntarios, como expone Musset desde un punto de vista histórico:

La decisión de un reasentamiento nunca es fácil de tomar, porque era percibida como un fracaso por los habitantes obligados no solo a abandonar su lugar de residencia y a perder su patrimonio territorial, sino también a cuestionar el estatus social que habían podido adquirir volviéndose miembro de pleno derecho de la ciudad — con todas las ventajas económicas y políticas que esta situación 
podía aportarles. Es por eso que la hora de la decisión era considerada como un momento crucial en la vida de la comunidad reunida alrededor de sus representantes, de su iglesia y de su rey (Musset, 2002, p. 203, traducción propia).

Esto nos da una idea de lo que representa, entonces, un reasentamiento no voluntario.

El reasentamiento era un proceso decisivo en el cual se ordenaba y determinaba a la población por reasentar. Por lo tanto, generaba también disputas entre ricos y pobres y entre los que querían moverse y los que no. Generalmente, los más ricos se desplazaban fácilmente; los pobres se rehusaban a salir para «no perder lo poco que tenían» (Musset, 2002, p. 203). El reasentamiento redefine la vida social y genera una situación crítica. «[...] Era importante conservar el nombre y el título de la ciudad abandonada, para justificar frente a los representantes del rey el mantenimiento de los privilegios adquiridos por la comunidad durante su historia, a veces corta» (Musset, 2002, p. 274).

El nombre tenía, también, un profundo valor simbólico, político y religioso (Musset, 2002, p 274). El cambio abría la necesidad de seleccionar los elementos de la vida anterior que serían conservados o eliminados.

Como hemos sugerido anteriormente, el reasentamiento se puede ver como un proceso crítico para los individuos y para la comunidad, ya que implica una serie de adaptaciones. A nuestro parecer, la esperanza puede verse como una adaptación a una situación previa de reasentamiento. Pascale Absi (2010) muestra de qué manera los mineros cooperativistas de Oruro (Bolivia) han redefinido la crisis a fines de los años 2000. En la situación que ella estudió, la crisis no es una situación de falta de ingresos, de baja de los precios del mineral, ni tampoco una ausencia de mineral, incluso prolongada. En este caso, la crisis define situaciones extremas, como la imposibilidad de trabajar, la enfermedad, la discapacidad, o incluso la muerte. Esta perspectiva «extrema» permite ver «lo peor» (la crisis) desde un punto de vista menos definitivo y con mayores esperanzas.

Por «crisis» entendemos entonces situaciones complejas, pero a priori reparables.

\section{El reasentamiento: un acto de poder}

Como Musset (2002), consideramos que el reasentamiento es un acto de decisión y de organización de población, es decir, un acto de poder. Cuando el reasentamiento está a manos de una empresa privada que «necesita» reasentar a una población para poder realizar sus objetivos, el acto representa un proceso de "gobernamentalidad» (Foucault, 2004). Es decir, de una manera práctica de gobernar, asegurando la supervivencia del poder, "satisfaciendo las necesidades de la sociedad que rige y buscar sus raíces en los intereses morales y materiales de su pueblo» (Rosanvallon, 2015, p. 282, 
traducción propia). La gobernamentalidad era eso: conocer el pueblo, «estudiar sus necesidades y explorar sus características» (Rosanvallon, 2015, p. 282). Foucault también evoca la gobernamentalidad como una forma "moderna» (a partir de los siglos XV y XVI) del Estado, ya no de gestionar un territorio a través de dispositivos administrativos, sino a través de la disciplina y la soberanía; una forma «de poder que tiene como blanco principal a la población» (Foucault, 2004, pp. 111-112, traducción propia). Además de la convivencia, nuestra mirada acerca de este contexto apunta hacia la comparación de la empresa minera con una entidad que gobierna, en el sentido que ordena, disciplina y sanciona en un territorio en el que ejerce su poder.

Por otro lado, Margier (2016) indica que el simple hecho de "residir» o "vivir» (habiter) es, en sí, un "acto eminentemente político» (2016, p. 48, traducción propia), ya que implica «estar en relación con los otros seres humanos» (Margier, 2016, p. 48). El reasentamiento llega a ser, entonces, el acto forzado — en el caso de los reasentamientos involuntarios - de decidir cambiar el lugar de residencia de un grupo de personas. En el caso que estudiamos, el objetivo inicial es desalojar al grupo de personas para aprovechar de los recursos del subsuelo. El lugar o las condiciones en que sean reasentadas las personas es, de por sí, una preocupación secundaria. El objetivo es extraer mineral.

A pesar de ello, el reasentamiento no debe ser visto (únicamente) como una dominación seca, brutal o violenta. La violencia y la relación de poder son ciertamente características intrínsecas. Pero sería un error pensar que no existen negociaciones o resistencias.

Además de un ordenamiento gubernamental de los espacios y de los individuos, el proyecto aplica en el espacio local nuevas temporalidades. El reasentamiento no es un evento puntual, tampoco es una etapa. Es necesario verlo, más bien, como un proceso largo e indefinido. La imprecisión — voluntaria o no- de un proceso manejado por una institución con poder, aumenta la precariedad de la condición de los futuros desplazados. Si se puede decir que el inicio de un proceso de reasentamiento empieza cuando este es oficialmente comunicado a la población, es más difícil afirmar con precisión en qué momento se termina. Siendo un cambio de «lugar propio» de vida, consideramos que el fin de un proceso de reasentamiento no existe socialmente. Técnicamente, este sería la instalación de la última familia en la ciudad nueva. Pero en términos sociales (o pragmáticos), el fin de un reasentamiento debería ser simplemente el nuevo inicio de una vida «normal»o conveniente, lo que nos parece imposible de evaluar. El contexto de «crisis» merece un tiempo más o menos largo de resiliencia ${ }^{5}$. En muchos casos, los reasentamientos

\footnotetext{
Faure (2008) indica, por ejemplo, que en los casos que estudió, en Europa, los hijos de las personas que fueron reasentadas en la década de 1970 por la construcción de represas hidroeléctricas van
} 
en distintas partes del mundo han dado lugar a procesos memoriales a través de los cuales la población desplazada recuerda su antiguo pueblo o ciudad a través de peregrinajes (Faure, 2008). Esto sería una prueba de que, años o generaciones después, el reasentamiento deja huellas, ya sean estas buenas o malas. El reasentamiento cambia la historia de una localidad.

$\mathrm{El}$ «acto de poder» se caracteriza a través de un protocolo más o menos fijo e institucionalizado (IFC, 2002, pp. 15-16), prácticamente como una medida política.

El IFC describe los pasos a seguir por toda entidad privada o pública responsable de un reasentamiento. En primer lugar, indica la necesidad de un mapeo temático de la zona afectada. Se identifican ciertas características como los lugares de vivienda, características topográficas y ambientales, recursos y tipos de uso de la tierra. Luego, se efectúa un "censo de las personas afectadas y su ubicación» (IFC, 2002, pp. 15-16). El tercer punto consiste en hacer un «inventario de los bienes perdidos, por hogares, empresas y comunidades». En cuarto lugar, se efectúan evaluaciones en cuanto a la economía y a las características sociales de las personas afectadas que debe incluir a todas las personas afectadas por el reasentamiento; es decir, no solo a las personas que se desplazarán, sino también a las personas que viven en las proximidades del lugar del futuro reasentamiento. El quinto punto tiene que ver con estudios analíticos cualitativos y cuantitativos donde se evalúan las encuestas y se definen baremos de indemnización. Se establecen también estrategias de sostenibilidad económicas y sociales para el futuro de las familias. El sexto y último paso consiste en consultar a la población para encontrar maneras de mitigar los efectos negativos del reasentamiento y definir "oportunidades de desarrollo" (IFC, 2002, p. 16). Este proceso que reúne un conjunto de medidas - mapear, censar, hacer inventarios, evaluar, definir baremos, identificar, determinar, etc.forma parte de una construcción de saberes políticos sugerida a las compañías mineras para una gestión política de la población.

El reasentamiento no es solo un proceso técnico: es una gestión política privada a mediano plazo con consecuencias a largo plazo. De manera esquemática estos fueron los procedimientos que siguió la empresa Xstrata para el reasentamiento de Fuerabamba.

\section{Los rumores: primeros signos del reasentamiento}

Acerquémonos ahora hacia el caso que nos interesa, en el proceso previo al reasentamiento de la comunidad de Fuerabamba.

al antiguo pueblo de sus padres. Como un peregrinaje, esto es posible cada veinticinco ańos, cuando vacían parcialmente la represa para su mantenimiento. La memoria de los lugares queda a través de las narrativas o de elementos visuales en los que se enganchan los recuerdos. 
Según la versión preliminar del estudio de impacto ambiental (EIA) del proyecto Las Bambas, la empresa sabía que iba a reasentar a la comunidad de Fuerabamba al menos desde 2004:

El reasentamiento previsible de Fuerabamba, que surgió primero como una posibilidad con la comunidad en 2004, también ha inducido cambio, incluyendo el crecimiento significativo de la población puesto que los comuneros han regresado de vivir de otros lugares para participar en el reasentamiento (Golder Associates, Vol. F, 2010, p. 4.18).

En 2004, Xstrata aún no se había instalado físicamente en la comunidad. El reasentamiento habría sido simplemente evocado en las primeras asambleas como una opción posible, pero lejana e incierta, sin plazos precisos. Durante varios ańos, el reasentamiento fue arrastrado como un rumor, creando preocupación entre las familias. Antes del anuncio oficial, el rumor ya hacía del reasentamiento una realidad virtual, poniendo a las familias en una condición de espera; la espera de ver los cambios de la situación, o la espera de una confirmación de la empresa. Como ya evocamos, a nuestro parecer, la situación de espera - tanto como sensación y como proceso temporal - no empieza al momento del anuncio oficial del reasentamiento. Empieza cuando las personas creen en la posibilidad de ser reasentadas. En todo caso, la posibilidad (o el rumor) de un reasentamiento se convierte en una posibilidad real cuando el rumor no puede ser contradicho por la empresa minera. Poco tiempo después del asentamiento físico de Xstrata en el territorio de Fuerabamba, durante el primer semestre de 2005, los rumores de un eventual reasentamiento ya corrían entre los habitantes de la comunidad y en los alrededores, en los discursos, y también en algunos documentos, como mostramos a continuación.

En un documento de 2005, donde la Agencia Nacional de Promoción de la Inversión Privada (Proinversión) promovía el proyecto Las Bambas, se mencionaba entre las condiciones sociales del proyecto un posible futuro reasentamiento de ciertas localidades vecinas del proyecto:

Compromisos asumidos por el ganador del proyecto minero Las Bambas. [...]

Reubicación de las comunidades afectadas en condiciones adecuadas, previo pago del justiprecio conforme a ley (Proinversión, 2005, p. 64).

A pesar de la falta de precisión, este documento público hacía oficial también la posibilidad y validaba las preocupaciones de la gente por un posible reasentamiento. Antes de 2006, el reasentamiento ya era señalado como un «tema crítico" por los habitantes de Fuerabamba (ProDiálogo, 2006, p. 45). Según un documento no publicado que había sido elaborado por un equipo de científicos 
sociales $^{6}$ encargados del plan de reasentamiento por Xstrata, el encuentro de la directiva comunal con la congresista Hilaria Supa Huamán durante el período 2006-2007 habría contribuido a mantener una relativa oposición al reasentamiento. El documento señala, en ese entonces, que la comunidad consideraba el reasentamiento como una amenaza y no como una oportunidad. Además, se precisa que los habitantes carecían de información sobre el proceso y los plazos, lo que causaba incertidumbre. Se necesitaron varias reuniones para que la población muestre mayor interés por el reasentamiento.

El documento indicaba que las familias querían ser reasentadas en la provincia misma (Cotabambas) y que rechazaba la oferta inicial de Xstrata de mudarse a un fundo de la provincia de Chumbivilcas (región Cusco). Además, se pedía a la empresa mayor transparencia en la información brindada y se exigía construir una relación de «socios estratégicos» entre la comunidad y la empresa (equipo PRAS, 2008, p. 30).

El reasentamiento había sido, también, un tema delicado que originó tensiones entre las familias de la comunidad, como indicaba este mismo documento: «[...] se ha prohibido en acta comunal, conversar sobre el tema y se ha dispuesto una multa de 1000 nuevos soles a quien acepte de alguna manera el proceso de reubicación o conversar sobre el tema» (equipo PRAS, 2008, p. 30).

El simple hecho de evocar el tema del reasentamiento — dice Musset hablando de los reasentamientos de ciudades en la historia americana- «separaba generalmente a la ciudad en dos grupos (partidarios y oponentes al desplazamiento)» (2002, p. 203). Los ricos tenían las posibilidades físicas de reasentarse y de construirse nuevos espacios de vida; los representantes de la Iglesia seguían atados a sus templos y a sus rentas. Los más pobres eran los que más se oponían a perder lo "poco que les quedaba"» (Musset, 2002, p. 203).

El primer plan de reasentamiento de la comunidad de Fuerabamba fue oficialmente expuesto ante la comunidad en marzo de 2008 (Golder Associates, Vol. F, 2010, p. 4.13).

Este plan preveía el reasentamiento de Fuerabamba hacia un terreno que Xstrata había comprado previamente, en el distrito de Colquemarca (provincia de Chumbivilcas, región Cusco). El fundo Yavi-Yavi tenía 3800 hectáreas, pero estaba ubicado a más de tres horas de Fuerabamba y se situaba a una altura de más de 4500 m.s.n.m. (IAG ${ }^{7}, 2010$, p. 16). La distancia y las características topográficas hicieron que la comunidad rechazase esta primera propuesta.

\footnotetext{
6 Equipo PRAS, 2008, Reasentamiento de la Comunidad Campesina de Fuerabamba (proyecto). Equipo PRAS.

7 «El IAG está conformado por personas con experiencia en temas comunitarios, sociales, ambientales, éticos y económicos que enfrentan comúnmente las empresas que operan en países en desarrollo.
} 
La población exigía proximidad al proyecto. La cercanía a Las Bambas iba a asegurar mejores oportunidades laborales y de negocio. También iba a asegurarles el acceso a los fondos del canon (IAG, 2010, p. 16). Este sería redistribuido por el Estado y la región, luego de que la empresa empezara la fase de explotación. Finalmente, la empresa encontró extensiones suficientes de terrenos relativamente adecuados para reasentar a la comunidad, y construir una ciudad nueva a la vez cerca del proyecto y cerca de su antigua comunidad. El futuro de la comunidad sería un centro urbano "moderno», con las comodidades de una ciudad. El centro urbano sería el lugar principal de residencia de las familias. El fundo Yavi-Yavi sería finalmente conservado como parte de la reposición de tierras y serviría como espacio productivo y experimental: «Se prevé que Yavi-Yavi se convertirá en una especie de gran operación ganadera» (Golder Associates, 2010, Vol. F, p. 4.66). La aceptación del lugar de reasentamiento fue fruto de varios meses de negociaciones y de contrapropuestas expuestas por la comunidad. Desarrollaremos este punto a continuación. A pesar de las discrepancias internas, finalmente llevada por la directiva, la comunidad decidió ser reasentada en conjunto: ni de forma parcial, ni de forma individual (Golder Associates EIA, Vol. F, 2010, p. 4.8).

\section{La temporalidad del proceso de negociación}

Inicialmente, la oficialización del reasentamiento causó desconfianza entre la población. Poco a poco, a través de programas de comunicación y de proyecciones de acuerdos y promesas de beneficios, se logró una mayor aceptación, primero entre las autoridades. Luego, ciertos liderazgos permitieron un convencimiento más amplio, al que también contribuyó la creación de comisiones que serían encargadas de mediatizar la comunicación entre la Comisión Central de Reasentamiento (CCR) y los habitantes.

Fue necesario un trabajo considerable para manejar las inquietudes iniciales de los hogares dentro de la comunidad y esto tomó algo de tiempo. Este trabajo incluía proporcionar tanta información como fuera posible acerca de los términos y condiciones potenciales de reasentamiento en varias reuniones, solicitando aportes para incorporarlos en los planes de reasentamiento iniciales, realizando visitas a los proyectos de Xstrata (exploración Las Bambas y la Operación Tintaya) y los sitios de reasentamiento potenciales, estableciendo una Comisión Central de Reasentamiento para comprometer a Xstrata para que realice la planificación para el reasentamiento

[...] En la actualidad, el IAG cuenta con seis miembros: cuatro miembros peruanos (Jaime Urrutia, Luis Barrenechea, Nicole Bernex y Carroll Dale) y dos miembros extranjeros (Rory Sullivan y Assheton Carter). En el Anexo 3 se presentan breves biografías de los miembros actuales del IAG» (IAG, 2010, p. 16). 
e incluyendo a los gobiernos distritales y provinciales en el proceso de planificación para el reasentamiento. Los hitos importantes durante este proceso de consulta inicial aparecen en el cuadro 1 (Golder Associates, Vol. F, 2010, p. 4.13). En él se puede apreciar el cronograma oficial de todo el proceso de negociación del reasentamiento indicado en la versión previa del EIA (2010).

\section{Cuadro 1. Hitos de consulta inicial, según Golder Associates}

Presentación de la estrategia de reasentamiento de Xstrata para la

Marzo de 2008

asamblea comunal de Fuerabamba

Presentación de la propuesta de reasentamiento de Xstrata a los líderes Noviembre de 2008 de la comunidad

Presentación de la propuesta de reasentamiento de Xstrata a la asamblea Diciembre de 2008 comunal

Presentación de la propuesta revisada de reasentamiento de Xstrata a los Abril de 2009 líderes de la comunidad

Creación de capacidades de los líderes de la comunidad por los Julio de 2009 gobiernos provinciales y distritales

Reunión de la asamblea comunal extraordinaria para discutir la Julio de 2009 propuesta revisada de reasentamiento de Xstrata

Distribución de información a hogares individuales Septiembre de 2009

Elección de los miembros del CCR y de la subcomisión Octubre de 2009

Creación de capacidad para los miembros del CCR y de la subcomisión

Octubre de 2009

Desarrollo por el CCR de una contrapropuesta de reasentamiento Noviembre de 2009

Negociación de los términos de reasentamiento entre Xstrata y el CCR Enero de 2010

Firma del acuerdo de reasentamiento entre Xstrata y Fuerabamba

Enero de 2010

Negociación y acuerdo con Chila y Choaqere sobre tierras para zona Febrero de 2010 urbana

Fuente: Golder Associates, Vol. F, 2010, p. 4.14.

A inicios del año 2008 se anunció el reasentamiento. Como muestra el cuadro, fueron necesarias varias asambleas y reuniones (noviembre 2008, diciembre 2008, abril 2009) para que la empresa presente un proyecto conveniente para la comunidad. El año 2008 fue un año de giros. Mientras el anuncio del reasentamiento seguía motivando el regreso de muchos emigrantes, el tema de los retornos empezaba a aparecer para muchos como un "problema».

En 2009, la comunidad se volvió más hermética. Para la negociación, se había pactado tácitamente cortar los contactos con terceros que podrían interferir en un proceso 
que se quería cerrado y exclusivo entre la empresa y la comunidad. A partir de 2009, ya no se aceptaba a personas extrañas (como acompañantes, amigos, etc.) a las asambleas generales. Los espacios sociales y políticos de la comunidad se volvieron exclusivos ${ }^{8}$.

Los temores que causaba el anuncio del reasentamiento, además de tres propuestas fallidas, habían llevado a la comunidad a exigir la intervención de nuevos actores. La comunidad pedía el apoyo de un mediador que pudiese negociar en favor de la comunidad y resolver los desacuerdos con la empresa.

Valentín C. es el autor [el gerente general de Las Bambas de 2009 a 2014]. Conjuntamente con el presidente de la comunidad [...]. La presencia del asesor se debe a estas cosas. Primero [...] con su primer gabinete, con Ronald L. [el gerente general de Las Bambas entre 2005 y 2008], se rechaza a la mina. Primero la comunidad de Fuerabamba rechaza cuando le traen la maqueta de la reubicación, para Yavi-Yavi. Entonces en su desesperación, la comunidad dice: "ique venga el Estado!, ¡que venga el gobierno regional!, ¡que venga, que venga!». Y de verdad le hace llamar el gobierno regional; entra a la comunidad. Ahí lo presentan al asesor: "aquí están unos profesionales, los van a ayudar. El gobierno regional los mandó» (señor P. Challhuahuacho, 19 de mayo de 2017).

En 2009, el Gobierno Regional de Apurímac envía a un intermediario que acompańaría a los dirigentes de Fuerabamba en el proceso de negociación. La meta era establecer una contrapropuesta de los programas de reasentamiento previamente presentados por la empresa y rechazados por la comunidad. El intermediario destacado por el Gobierno regional se volvió asesor de Fuerabamba entre 2009 y 2014. A través de un fondo manejado por la comunidad, el asesor era financiado por Xstrata. Otro intermediario había sido designado para acompañar el proceso de negociación. Este era representante de la municipalidad de Challhuahuacho. Estos dos miembros externos, representantes de dos instituciones públicas que hasta entonces habían mostrado un franco interés por el proyecto, iban a ser facilitadores del proceso de diálogo durante las negociaciones entre Xstrata y Fuerabamba.

El 29 de diciembre de 2009 se realizó un «compendio de acuerdos entre el comité central de negociación de la comunidad de Fuerabamba y los representantes del proyecto minero Las Bambas operado por Xstrata Cooper». El documento, de 36 páginas, fue firmado por una decena de personas, entre las cuales estaban el representante de la municipalidad distrital de Challhuahuacho, el gerente general del proyecto minero Las Bambas y un conjunto de autoridades comunales de Fuerabamba.

\footnotetext{
8 La exclusión de gente "extraña» es un síntoma de una modificación de orden político. Rosanvallon (2015, pp. 221-222) evoca, por ejemplo, que en el siglo XVIII, el término de «extraños» empezó a ser usado en las asambleas de Francia y Gran Bretańa para designar el público admitido desde las tribunas. «La denominación sugería que un cierto espíritu de "unidad” había marcado el mundo parlamentario desde sus orígenes» (traducción propia).
} 
El 18 de noviembre del 2009, la empresa Xstrata recibió de la comunidad de Fuerabamba el documento conteniendo la contrapropuesta para la negociación del reasentamiento involuntario de dicha comunidad, tras lo cual se conformaron las delegaciones de negociación de ambas partes, las mismas que fueron acreditadas debidamente mediante designación por la Asamblea General Extraordinaria de la Comunidad (Comisión Central de Negociación de la Comunidad Campesina de Fuerabamba) y mediante designación directa de la empresa en caso de la Comisión de Negociación de Xstrata.

Luego de reuniones de negociación sostenidas en el local Cusi Yachana Wasi de la comunidad de Fuerabamba entre los días 11 al 24 de diciembre, se ha logrado alcanzar consenso para cada uno de los ejes temáticos contenidos en la contrapropuesta, los mismos que se adjuntan a la presente minuta y que serán rubricados por parte de los negociadores acreditados de la comunidad y la empresa Xstrata, así como por el representante de la municipalidad de Challhuahuacho ingeniero Juan H. y el representante del gobierno regional de Apurímac Sr. Armando B. y actuando ambos como veedores/asesores del proceso de negociación o requerimiento de la comunidad de Fuerabamba.

Con la rúbrica de todas las partes en este documento, se da por concluido el proceso de negociación y quedan expeditos los acuerdos para su aprobación y ratificación por parte de la Asamblea General de la Comunidad en la reunión del próximo 11 de enero 2010, programada entre ambas partes, la misma que deberá ser convocada por la Directiva de la comunidad de acuerdo con lo establecido en su reglamento y en las normas legales aplicables.

El contrato donde la comunidad de Fuerabamba y la empresa minera Xstrata cierran el compromiso del reasentamiento fue establecido en una Asamblea General extraordinaria que se dio a cabo los días viernes 22 y sábado 23 de enero de 2010 . En este contrato se establecía un plan de reasentamiento con un paquete de compensaciones de trece ejes de desarrollo, oficialmente mediante un "proceso voluntario, libre e informado» (Choquenaira, 2010, p. 31).

El viernes 11 de febrero de 2011 hubo una reunión técnica entre representantes del Gobierno regional y los dirigentes de la comunidad de Fuerabamba. El lunes 14 de febrero se dieron las primeras reuniones sectoriales respecto del reasentamiento de Fuerabamba entre las autoridades comunales, representantes del Gobierno regional y el gerente de RRCC de Las Bambas de ese entonces, Livio Paliza. Las familias de la comunidad querían ser reasentadas a proximidad del proyecto. Un terreno ubicado entre Chila y Choaqere — dos comunidades ubicadas a unos $15 \mathrm{~km}$ de Fuerabamba — fue identificado para acoger la nueva zona urbana?.

\footnotetext{
9 Musset (2003) indica que, en la historia latinoamericana, los desplazamientos de población se hicieron en su mayoría en un perímetro de $10 \mathrm{~km}$ alrededor de la localidad original. Mas allá, se corría el riesgo de un abandono de la ciudad nueva hacia otros territorios.
} 
Cuadro 2

1 Educación inicial, primaria y secundaria en un solo complejo educativo

2 Educación superior

3 Desarrollo de capacidades

4 Saneamiento básico

5 Reposición de tierras

6 Agricultura

7 Ganadería

8 Infraestructura económica

9 Atención prioritaria del adulto mayor, madres solteras, viudas, huérfanos y discapacitados

10 Oportunidad de empleo en la mina

11 Desarrollo económico local

12 Fortalecimiento organizacional

13 Salud

Fuente: Choquenaira, 2010, p. 31.

Ambas comunidades aceptaron la cesión de una parte de sus territorios a cambio de una serie de beneficios acordados con Xstrata, como la "participación en los programas de desarrollo sostenible que Xstrata financiará para contribuir con la calidad de vida de las personas tanto en Fuerabamba como en las dos comunidades de acogida» (Golder Associates, Vol. F, 2010, p. 4.63).

\section{Impactos previstos: ¿̨impactos mitigados?}

Los impactos potenciales del reasentamiento son numerosos y diversos. Los estudios de impacto, así como los propios estudios de responsabilidad social, establecen sistemáticamente listas de riesgos potenciales durante las diferentes etapas de operaciones. Para Fuerabamba y el entorno del proyecto minero, estos fueron muy diversos. A grandes rasgos, el Volumen A de la versión previa del EIA expone algunos efectos indeseables que, se prevé, presentaría el reasentamiento. Entre ellos, se habla de la pérdida de accesos a territorios y actividades tradicionales y la pérdida física de la infraestructura comunal, como también de los medios que permitín la reproducción social de la comunidad. También se evocan la suspensión de las actividades comerciales, la posible generación de conflictos, entre otros, con la población de acogida, la transformación de las redes sociales establecidas y la fragilización de la población vulnerable (ancianos, viudas, niños, madres solteras, discapacitados, etc.) (Golder Associates, Vol. A, 2010, p. 112). Estos impactos potenciales son listados en las recomendaciones del Banco Mundial y fueron evocados en muchas ocasiones por varios investigadores ${ }^{10}$.

10 Véase, entre otros, Sebenius et al., 2005; Downing, 2002 y Downing y García Downing, 2001. 
Las comunidades «de acogida» también fueron identificadas como actores que podían presentar problemáticas directamente ligadas al reasentamiento de Fuerabamba. Estas eran la presión sobre los recursos naturales y sobre la infraestructura comunal existente (escuela, centro de salud, etc.), o la posible aparición de conflictos por la percepción de una falta de equidad de repartición de recursos con la comunidad que se instalaría (Golder Associates, Vol A, 2010, p. 112).

Los impactos potenciales son directamente confrontados a una serie de medidas tomadas por la empresa para contrarrestarlos. De cierta manera, lo "potencialmente negativo» se diluye tras retóricas institucionales de prevención de riesgos o «mitigación». Las promesas institucionales de mitigación permiten la creación ideal del futuro que aparece como «indiscutiblemente mejor», en teoría, que la situación inicial. Los riesgos estarían bajo control, el futuro estaría asegurado.

Se repondrá cualquier ingreso o fuente de subsistencia perdido o abandonado como consecuencia del reasentamiento. No sólo se reemplazarán las tierras y bienes inmuebles, sino que experimentarán un aumento en cantidad, calidad y/o dimensiones. Se garantizarán los medios de subsistencia mediante la ayuda para restablecer las actividades agrícolas y ganaderas, mediante el empleo continuo con Xstrata durante la construcción, como es el caso actualmente, y durante las operaciones del Proyecto a través de un puesto a tiempo completo con Xstrata para al menos un miembro de cada familia reasentada.

La infraestructura de la comunidad, incluyendo centros de salud y educativos, se reemplazarán, una vez más con un estándar mejorado. Por último, los proyectos de desarrollo sostenible crearán oportunidades para aumentar la generación de ingresos aumentando la productividad de la agricultura y ganadería y apoyando el desarrollo comercial (Golder Associates, Vol A, 2010, p. 113).

Las proyecciones escritas en el EIA, así como los acuerdos realizados con la comunidad, fueron, más que relaciones contractuales, contratos de confianza en los que lo prometido, lo acordado y lo firmado era en todos los casos presentado por la empresa y aceptado por la población como algo «mejor». A pesar de la subjetividad del término (¿qué es «mejor»?), se consideraba en un relativo consenso que el reasentamiento iba a aportar una situación «mejor» a la comunidad y a sus miembros. Esta condición parece indispensable para poder proyectarse en un reasentamiento. Los riesgos potenciales de un reasentamiento, así como las respuestas institucionales previstas, son formulados en las recomendaciones que emiten el Banco Mundial y el IFC.

\section{Después será mejor; la retórica de lo «igual o mejor»}

Las instituciones reguladoras de los reasentamientos han aplicado de manera tácita la norma — que en realidad es una imagen ideal— de que la vida, la infraestructura, 
la calidad de las tierras, y demás elementos de la vida cotidiana deberán ser iguales o mejores de los que tiene la población antes del reasentamiento.

Los derechos de reasentamiento pactados hasta la fecha entre la comunidad de Fuerabamba y Xstrata son generosos a favor de la comunidad. Las familias, en vez de los hogares, se reasentarán y se les proveerá viviendas nuevas, con todos los servicios, de un tamaño y estándar significativamente mayor al de la mayoría de casas en el actual Fuerabamba (Golder Associates, Vol. A, 2010, p. 112).

Cabe volver a señalar que las recomendaciones de dichas instituciones no son vinculantes: se deja a las empresas tomar las decisiones acerca de los reasentamientos que manejan, según las normas nacionales de los países donde desarrollan sus actividades, según sus políticas empresariales de desarrollo, además de las recomendaciones de las instituciones ya citadas.

De esta manera, el EIA señalaba que las viviendas iban a tener un diseño «arquitectónico y antisísmico», que cada hogar iba a tener: "por lo menos dos entradas, para seguridad y separación entre las actividades domésticas y comerciales en el hogar, que se iban a realizar usando "materiales modernos", que las ventanas iban a tener "mejor iluminación y ventilación" y que el diseño de las casas impediría la pérdida de calor» (Golder Associates, Vol. F, 2010, p. 4.65).

La proyección hacia un futuro mejor es transversal al imaginario minero, no solo caracteriza a las narrativas de reasentamiento. La minería arrastra consigo imágenes profundas de mejora social y económica y, hasta ahora de manera frecuente, de «civilización» (Puerta, 2009). La actividad minera parece mantener una retórica que se renueva de manera constante a través del tiempo. La «narrativa utópica», característica de la minería posterior a la crisis económica en Argentina — por ejemplo_ era una retórica compartida por las autoridades políticas y el sector minero para promover la minería como el sector que «salvaría» a la economía argentina en los años 2000 (Boccardi et al., 2008).

\section{El reasentamiento se orienta con recomendaciones, no con leyes}

El grupo del Banco Mundial es, desde hace más de tres décadas, una referencia global sobre reasentamientos de población realizados por razones de proyectos de desarrollo. Las minas a tajo abierto, como es el caso del proyecto Las Bambas, forman parte de este tipo de proyectos, al igual que la construcción de represas hidroeléctricas, de vías de comunicación, de ordenamiento urbano. Las recomendaciones emitidas por el Banco Mundial no son vinculantes, pero siendo un banco financiador de grandes proyectos, sus lineamientos generalmente son tomados en cuenta por las empresas promotoras. Las recomendaciones del BM buscan ayudar a las empresas a desarrollar sus actividades tomando en cuenta el entorno social y para mantener «limpia» su imagen corporativa. 
Por otra parte, para el reasentamiento se tomaron como referencia «los estándares internacionales de la Corporación Financiera Internacional (IFC) y de la Organización Internacional del Trabajo (OIT)» ${ }^{11}$. La empresa también se ha orientado siguiendo los lineamientos de las políticas corporativas de Desarrollo Sostenible como «división operativa» de Xstrata PLC (MEM, 2011). Según este documento, la empresa siguió estos lineamientos:

- Política de desarrollo sostenible, representa el compromiso con el balance de las consideraciones sociales, ambientales y económicas.

- Estándares de desarrollo sostenible, la empresa ha adoptado 17 estándares de salud, seguridad y medio ambiente,

- Consulta y participación con los grupos de interés para desarrollar relaciones de largo plazo,

- Se realizará esfuerzos para evitar la necesidad del reasentamiento, pero cuando sea necesario se realizará tomando como referencia la Norma de Desempeńo 5 del Banco Mundial/Corporación internacional de Finanzas (MEM, 2011).

En el marco de Las Bambas, se tomaron en cuenta dos ejes normativos. Por un lado, Xstrata siguió los lineamientos de su política corporativa. En ella entran aspectos de ética empresarial que implican también la imagen de la empresa. En segundo lugar, este reasentamiento tomó como base una serie de leyes y de normas legales relativas a las actividades que iba a implicar la actividad minera, en conjunto con el gobierno del Perú y el Ministerio de Energía y Minas (MEM, 2011). En el informe de una Resolución directoral ${ }^{12}$, se aprecia la «opinión técnica sobre el reasentamiento de la población de Fuerabamba» emitida por el director de Ordenamiento Territorial y destinada al director nacional de Urbanismo.

Según este documento, las bases legales y normativas que Xstrata tomó en cuenta para el reasentamiento fueron las siguientes:

- Constitución Política del Perú

- Ley 28611, Ley General del Ambiente

- Ley 27446, Ley del Sistema Nacional de Evaluación de Impacto Ambiental

- D.S. 028-2008-EM, Reglamento de Participación Ciudadana de la Ley General del Ambiente

- R.M. 304-2008-MEME/DM

11 Norma de Desempeño 5: Adquisición de Tierras y Reasentamiento Involuntario (IFC, 2006); Notas de Orientacion 5 correspondiente (IFC, 2007); Manual para la preparación de un Plan de Acción de Reasentamiento (IFC, 2002) (MEM, 2011).

12 INFORME 113-2010-VIVIENDA-VMVU/DNU/DOT de la Resolución Directoral 073-2011-MEM/AAM. 
- Ley 26505, Ley General de la Inversión Privada en el Desarrollo de las Actividades Económicas en las Tierras del Territorio Nacional y de las Comunidades Campesinas Nativas

- Ley 24656, Ley General de Comunidades Campesinas

Notamos que se toman en cuenta las diferentes dimensiones de un reasentamiento, pero no se habla explícita o legalmente de reasentamiento. Esto significa que, en otros casos de reasentamiento, el marco normativo tomado en cuenta puede ser diferente.

La Resolución Directoral concluye, con la firma del director de Ordenamiento Territorial, que:

En este contexto, opinamos que el estudio ha cubierto todas las previsiones del caso que permitan a la población afectada restablecer sus niveles de vida en mejores condiciones que las actuales. [...] Finalmente, en vista de lo expuesto y luego de revisar toda la documentación presentada, opinamos favorablemente respecto al estudio del Plan de Reasentamiento presentado para el Proyecto Minero Las Bambas, presentado por Xstrata Tintaya S.A. (MEM, 2011).

En ausencia de un marco legal específico para reasentamientos con estas características (involuntario, y por causa de "proyectos de desarrollo»), las empresas mineras hacen valer su «buena fe» y su reputación de empresa tomando como bases las recomendaciones del Banco Mundial y una serie de leyes de los países en los que desarrollan sus actividades. Atribuyéndose, de cierta forma, un poder de decisión legal (las leyes y normas) y política (gestionar a cientos de familias), la empresa aparece una vez más con el rol de una institución política.

\section{EL PODER POLÍTICO PRIVADO}

\section{La espera, lo ineluctable y la construcción de un proceso largo}

Volvamos al caso de Fuerabamba. El proyecto las Bambas implicó la «necesidad» ${ }^{13}$ de reasentar a esta comunidad campesina. El uso del término necesidad es naturalizado en los documentos emitidos por el proyecto minero (EIA) y por las entidades del Estado que lo avalaron o promovieron (véase MEM, 2011). Esto revela, de cierta forma, hasta qué punto el reasentamiento es expuesto (y percibido por la institución) como un hecho, un acto ineluctable sin alternativa. Durante nueve años, la comunidad y la mina convivieron física y socialmente dentro del territorio

\footnotetext{
13 El uso del término de necesidad es constantemente naturalizado; es usado, a la vez en los documentos emitidos por el proyecto minero (EIA) como por las entidades del Estado que lo avalan o promueven (véase MEM, 2011).
} 
comunal (2005-2014), una convivencia que fue oficialmente aceptada y que daba lugar a una serie de beneficios para la comunidad. Una relación preferencial se creó entre la mina y la comunidad. Esto ha formado un marco discrecional, creando interacciones particulares, interdependencias y actitudes paternalistas de la empresa.

De forma distinta que los casos de reasentamiento en contextos de conflicto armado o de catástrofes naturales — donde el reasentamiento es un fin-, en el caso minero el reasentamiento solo es un medio: se requiere el reasentamiento de ciertas localidades para poder explotar el subsuelo. Sin embargo, el reasentamiento se presenta a través de las construcciones retóricas corporativas como un fin. Es sugerido como un hecho ineluctable para el cual se ha preparado un protocolo y se ha previsto el futuro ${ }^{14}$.

En este sentido, el reasentamiento cierra y anula los futuros locales posibles imponiendo uno dibujado a partir de esquemas empresariales, ya que "no existe legislación nacional sobre el reasentamiento de poblaciones en proyectos mineros» (MEM, 2011).

\section{La promesa: la temporalidad al servicio de la política}

Esta situación de extrema proximidad, con relaciones interpersonales cotidianas, dio cabida al surgimiento de la "promesa» como retórica sistemática del relacionamiento cercano. Contractuales o no, las promesas permitieron poner tácitamente a las personas «administradas» en una situación de espera.

Desde su llegada a la provincia de Cotabambas, la empresa abrió oportunidades laborales, capacitaciones y propuso becas para los jóvenes como parte de su política de responsabilidad social empresarial (RSE) y también como dispositivo de aceptación social. Estos beneficios fueron distribuidos a las poblaciones del área de influencia, pero se concentraron mayormente hacia Fuerabamba, vecina a la pequeña ciudad de Challhuahuacho.

La promesa impone de por sí un reporte temporal hacia el futuro (Chateauraynaud, 2012, p. 10). El autor define la promesa como un proyecto llevado por un actor que busca convencer a otros. Su credibilidad depende del lapso del que dispone y de una articulación equilibrada entre el «ya» y el «todavía» (Chateauraynaud, 2012, p. 10). Las promesas aparecen como proyectos bipolares: por un lado, tienen un aspecto ideal o prototípico para las entidades (actores o instituciones) que las emiten. Por otro, pueden aparecer como proyectos imposibles de cumplir. Sea cual fuere el resultado (o lo que se espera), la proyección temporal permite poner en espera a las personas.

\footnotetext{
14 Así como la previsión del «cierre de mina» (varias decenas de años en el futuro), el reasentamiento es una dimensión del proyecto minero que también es "prevista» y dibujada por la empresa como un «plan» de futuro para las familias y la comunidad.
} 
Los beneficios dados y "por dar» a los habitantes de la comunidad fueron uno de los dispositivos de puesta en espera que emitió la empresa para con la comunidad a través de las promesas. El trabajo, así como las becas para los jóvenes, los talleres y las capacitaciones estuvieron a raíz de los tiempos de espera. La espera puede verse como un espacio dejado vacío que revela una relación de poder. Por ejemplo, la espera del trabajo explicada por Cingolani ilustra de qué manera la dimensión temporal y «acordeónica» de la incertidumbre crea inestabilidad y genera precariedad.

La generalización de lo provisorio, sin embargo, no supone tanto una inestabilidad efectiva del trabajador como una inestabilidad potencial. La revocabilidad posible es aquí más fundamental en cuanto a la relación de sujeción que la modularidad misma. Lo temporal va junto, comúnmente, con la dimensión de espera que es generalmente connotada en el sentido [...] de «libertad condicional» —es decir, en espera de juicio_- o como se dice también, "con carácter provisional» cuando se habla de una suma [de dinero] entregada cuando se espera un juicio (Cingolani, 2012, p. 124, traducción propia).

A través de la precariedad laboral, Cingolani permite apreciar la espera con una connotación agobiante y condicionante. Por un lado, el que espera no sabe hasta cuándo lo hará; por otro, tiene que mantener una actitud constante de "puesta a disposición». Asegurar constantemente su «empleabilidad» carga de incertidumbre la espera de las personas (Cingolani, 2012, p. 124).

El trabajo temporal pone al asalariado en la disposición de «ir hacia», [es decir] a ponerse a disposición. De cierto modo, hay que poder sacar las consecuencias en términos de disposiciones en este proceso de adiestramiento temporal de los asalariados (Cingolani, 2012, p. 131, traducción propia).

Es entonces la alternancia de tiempos de espera y tiempos de incertidumbre lo que causa una precariedad general, ya no solo en términos económicos, sino también en términos sociales o individuales. En contextos como este, la aceptación local de la actividad minera se logra en parte por la atribución de puestos (temporales) de trabajo. Por un lado, empleando personal no calificado de manera rotativa, la empresa muestra tasas de empleo potencialmente elevadas, sin precisar que muchos empleados solo trabajaron algunos meses en el año. Por otro, la alternancia de tiempos de trabajo y de no trabajo es lo que Cingolani (2012) llama «dispositivos precarios». En Fuerabamba, ponerse a disposición significaba mostrar presencia constante en la comunidad, pero también seguir los pasos de un orden social «minero» impuesto a la vez por la empresa y por la directiva durante varios años en la comunidad. La "disidencia» podía anular los derechos al trabajo de algunos por decisión de la directiva o de la comunidad en conjunto. En este sentido, la espera de nuevas temporadas de trabajo estaba condicionada a respetar el orden social local. 
Durante varios años antes del reasentamiento, las actitudes críticas hacia la directiva o hacia la empresa eran amenazadas con sanciones, excluyendo a los disidentes de los beneficios futuros ${ }^{15}$. La espera de beneficios permitía entonces una suerte de "puesta a disposición» de la comunidad que permitía al proceso de preparación del reasentamiento fluir con menos quejas y conflictos.

\section{Vulnerabilidades y posibilidades en un territorio de espera}

Después de los rumores (2004), el reasentamiento se convirtió en realidad a partir del anuncio oficial (2008) por la empresa. A partir de ese entonces, podemos decir que la comunidad se convirtió en un «territorio de espera» (Vidal y Musset, 2015). La puesta en marcha de un plan de reasentamiento, la convocación de asambleas generales, así como la organización de reuniones entre dirigentes empresariales y comunales fueron los primeros hechos físicos del inicio de un proceso, y de la situación de espera.

La espera se abrió como un espacio temporal indefinido donde se construyeron esperanzas y temores. La incertidumbre de un futuro «otro» en un lugar desconocido, que sería creado ex nihilo, llenaba de dudas y temores a las familias. Debido a ciertas incomprensiones entre la empresa y la comunidad, desde 2010 ya se escuchaban comentarios de la población de que el reasentamiento era inminente. Entre 2011 y 2012, varios interlocutores afirmaban que el reasentamiento se haría «quizás el próximo año».

En 2010, un equipo de la empresa Sodexo realizaba talleres, capacitaciones y charlas en su local de Challhuahuacho, con algunos grupos de Fuerabamba. En una de las charlas, se evocó el tema del reasentamiento. Esta sería una ocasión de hablar del tema fuera del ambiente comunal y de sus tensiones con un equipo de personas dispuestas a escuchar las dudas de los participantes; el equipo de Sodexo contaba con gente diplomada en ciencias sociales y psicología.

En una de estas charlas resaltó que varias personas percibían el futuro reasentamiento con una suerte de "preocupación altruista». Varias personas se pusieron a llorar cuando, en la conversación, se proyectaron hacia el futuro. Sentían tristeza por sus padres, adultos mayores con poca experiencia urbana, que ya les habrían comentado sus temores.

En una perspectiva de profundos cambios, los elementos cotidianos de la vida rural se convertían en los frenos del futuro urbano. El miedo de las cocinas a gas fue evocado varias veces, así como la sensación de encierro que se puede sentir a veces al interior de una ciudad.

15 Una parte de las compensaciones monetarias debían ser entregadas después de que se hiciera efectivo el reasentamiento. 
Nosotros no queremos ser reubicados. Prácticamente, vamos a vivir como en una cárcel. Un día estuve internado en un hospital, y nadie respondía detrás de la ventana. El único consuelo es que no vamos a estar lejos de aquí (señora Ermelinda ${ }^{16}$, Challhuahuacho, 2010).

Yo he pensado en mis familiares, mis abuelos, he pensado mucho; en mi papá también y en mis tíos. Para mí [el reasentamiento] no cambiará nada [...]. Hay gente que dice «tengo miedo de prender la cocina a gas». Aquí, es gratis, la madera, la bosta... (señora Sofía, Challhuahuacho, 2010).

En nuestra opinión, estos temores están relacionados con costumbres — deberíamos decir «acostumbramientos»— sociales y no con barreras, «idiosincrasias», cosmologías o alguna supuesta «cultura» propia de la población andina. Al mismo tiempo que estas personas evocaban sus temores propios y los de las personas mayores, percibían también el reasentamiento como un hecho ineluctable, una fatalidad que para muchos era triste y dolorosa, pero que para otros representaba una oportunidad, sobre todo para los más jóvenes. La espera se construyó como un proceso dialéctico y activo de esperanzas y miedos.

\section{Gobernar el tiempo, clasificar a la población}

El ordenamiento de la vida material y física de la comunidad ha sido una etapa fundamental para la preparación del reasentamiento por la empresa. En este proceso de «censo» general, se cristalizó el poder político de la empresa minera no solamente como una entidad de gestión, sino también prácticamente de gobierno. Su tarea era fijar las reglas con la comunidad, determinar a los beneficiarios, hacer un inventario de bienes por familia y fijar límites temporales después de los cuales el proceso de conteo general se terminaría. Después de la fecha límite, la situación sería irreversible.

Veamos la definición de esta etapa por la CFI:

Fecha límite: Fecha de terminación del censo y del inventario de bienes de las personas afectadas por el proyecto. Las personas que ocupen la zona del proyecto después de la fecha límite no tendrán derecho a indemnización ni a recibir asistencia para el reasentamiento. Tampoco se pagará una indemnización por los bienes inmuebles (como construcciones, cultivos, árboles frutales y arboledas) establecidos después de la fecha de terminación del inventario de bienes, o de una fecha mutuamente acordada (IFC, 2002, p. 103).

La gobernabilidad ejercida por la empresa minera se cristalizó, entre otros aspectos, en la limitación del número de beneficiarios, que es una medida prevista

16 Los nombres son seudónimos. 
por la CFI (CFI, 2002, p. 19), pero también en la definición de una fecha límite para determinar a los beneficiarios.

Uno de los aspectos fundamentales del reasentamiento en contexto minero es, de manera práctica, la contabilidad. La construcción de una ciudad nueva requiere datos precisos para la puesta en marcha de un proceso de construcción urbana o urbanizada. Para ello, es necesario determinar las realidades locales, fijarlas, calificarlas y poder cuantificarlas. Estos aspectos se asemejan de cerca a la labor ordenadora, normativa y clasificadora de una administración política.

Se tuvo que calcular para el reasentamiento cuántas casas se iban a construir en la ciudad nueva. Esto implicaba determinar previamente el número de «beneficiarios». Esta misión fue compleja y controvertida, ya que la decisión de cerrar el número de comuneros de una comunidad no es usual. Para determinar el número, se tuvo que fijar una fecha límite. En sí, se trata de una decisión arbitraria dependiente del proyecto. Ciertos empadronamientos, así como ciertos rechazos, fueron arbitrarios debido a lazos de parentesco o a roces con los dirigentes comunales.

Hervé (2012) explica cómo se articuló en este caso el proceso oficial de empadronamiento con la situación de esta comunidad. Situaciones particulares como esta permiten repensar las normas oficiales. Sencébé (2004) explica, por ejemplo, lo fluidas que son las fronteras de la pertenencia o de los sentimientos de pertenencia social y territorial (estar aquí, ser de aquí) y cómo estas categorías se (re)componen según las dinámicas sociales a las que se confrontan las trayectorias individuales.

Existen reglas para saber de manera precisa quién forma parte de una comunidad y quién no. El padrón comunal, puesto al día cada dos ańos, indica los nombres de los miembros empadronados de la comunidad. El reglamento general de las comunidades campesinas determina también cuál es el mecanismo social, las condiciones y los deberes para formar parte de una comunidad. Sin embargo, en los confines de las reglas existen espacios porosos de interacciones sociales que admiten transacciones particulares. Algunos casos paradigmáticos permiten ilustrar la «arbitrariedad» en la selección o no de algunos beneficiarios; es decir, algunas personas que fueron aceptadas (o no) en el padrón comunal. Con el poder que adquiere - por el hecho de ser intermediarios entre la empresa y la comunidad-, la junta directiva puede «habilitarse» a tomar decisiones arbitrarias. Esto ocurrió con varias personas que, habiendo entrado en conflicto con algún miembro de la directiva, no fueron consideradas como beneficiarias.

\section{La construcción del futuro}

La nueva situación, impuesta e indefinida, impide entender con claridad los futuros posibles (o imposibles). Esta situación indefinida que se produce durante la situación de espera podría presentarse como la producción de futuros híbridos 
compuestos a la vez de promesas (allá será [...], allá tendrán [...]), de esperanzas desconocidas («algo mejor»), de esperas y de profecías (algo bueno o malo pero ineluctable) (Ver Chateauraynaud, 2012).

Algunos dispositivos que fueron pensados por la empresa presentaban explícitamente una proyección temporal. La seguridad, la prevención de riesgos o su mitigación forman parte de las bases retóricas empresariales, y más aún mineras ${ }^{17}$. La previsión de la eventualidad integra la cultura corporativa y esta lógica es generalizada en el espacio que ocupa el proyecto minero. La gente que trabaja o que aspira a trabajar en el proyecto está absorbida por esa lógica y adopta o se dispone a adoptar los códigos de seguridad y prevención impuestos para trabajar «en» $\mathrm{o}$ "para» el proyecto.

Para Fuerabamba, como para el conjunto de las comunidades del área de influencia del proyecto minero, el futuro fue imaginado $-\mathrm{y}$ de cierta forma «previsto»— por la empresa con un conjunto de transformaciones sociales («descampesinización»), laborales (mayor tiempo dedicado a actividades nuevas y más urbanas) y económicas (mayor monetización de la economía). La implicación social del proyecto minero en la economía local ha permitido desarrollar una serie de actividades y dinámicas nuevas más o menos ligadas al proyecto. Xstrata ha promovido el «desarrollo de pequeños negocios primero para suministrar al proyecto» (Golder Associates, Vol. F, 2010, p. 4.67). Más allá de los talleres de electricidad, manejo o mecánica, se promovía el «desarrollo de capacidades» que permitiesen a las familias generar nuevos ingresos con actividades que se articularían a las nuevas realidades económicas locales. También se facilitó el crédito para que los habitantes de Fuerabamba realicen inversiones mayores y se desarrollaron capacitaciones en «marketing y capacidades de gestión financiera y comercial».

La formación o capacitación de los habitantes de Fuerabamba formó parte de una dinámica fuerte de proyección hacia un futuro dibujado con rasgos mineros, urbanizando la vida cotidiana y diluyendo la necesidad y las posibilidades de seguir actividades agropecuarias de subsistencia. El traslado induciría la urbanización de la vida de campo. La «descampesinización» es un fenómeno común en la historia de la minería (antigua y moderna), pero el reasentamiento iba a acelerar el fenómeno. De esta manera, se preparaba a los habitantes a transformaciones económicas del entorno, pero se sugería, también, una nueva manera de vivir y de integrarse a la «modernidad» prevista localmente.

\footnotetext{
17 En la versión previa del EIA Vol. F (2010, pp. 2.114-2.123), se mencionan, por ejemplo, los impactos esperados sobre el tráfico, el aire, el ruido, la salud y seguridad públicas, los recursos biológicos, la estética visual, la suma de efectos ambientales y los impactos residuales.
} 
El Programa de Formación y Desarrollo Fuerabamba T’ikariy Wiñaypaq (Fuerabamba Florece por Siempre) se implementó en 2009. Bajo este programa, alrededor de 500 miembros de la comunidad de Fuerabamba reciben capacitación en una serie de oficios asociados con la industria minera, como construcción, mantenimiento de vehículos y hospedaje. El programa se está implementando con la ayuda de una serie de instituciones locales y está abierto a los miembros de la comunidad mayores de 16 años (AIG, 2010, p. 15).

\section{LA URBANIZACIÓN DE LA VIDA RURAL}

[...] De hecho, los caseríos se convertirían en barrios (Golder Associates, Vol. F, 2010, p. 4.48).

\section{Arquitectura y sociabilidad}

Hoy en día, la ciudad nueva está ubicada a poco más de $15 \mathrm{~km}$ de su territorio original.

La comunidad original se había formado a lo largo de una cuenca recorrida por un río y se dividía en trece caseríos, a veces distantes entre ellos por más de 5 kilómetros en un territorio de 4774 hectáreas; en cambio la ciudad nueva ha sido construida sobre un conjunto de plataformas realizadas por la voladura de un flanco de montańa y con obras hechas con maquinaria pesada. La zona urbana y habitable de la ciudad nueva está conformada por cuatro calles largas y por un conjunto de calles más pequeñas que cortan la ciudad por lo ancho. Hasta inicios de 2017, la ciudad nueva tenía los restos físicos de los dispositivos de vigilancia que permitían filtrar las entradas. Hasta el mes de enero, los habitantes debían identificarse al entrar a su comunidad. Las dos garitas de seguridad quedaron vacías entre enero y abril de 2017, y luego fueron retiradas.

El espacio habitable de la ciudad nueva se concentra en 12 hectáreas, incluidas en un territorio de 350 hectáreas donde se hallan los diferentes módulos que constituyen la nueva estructura urbana:

- Centro Educativo Politécnico (wawa wasi, Pronoei, Inicial, Primaria, Secundaria)

- Centro de salud

- Centro de capacitación

- Planta de tratamiento desagüe (ya se consideró en saneamiento básico)

- Rellenos sanitarios

- Losas deportivas

- Asilo de ancianos

- Tres iglesias

- Mercado de abastos

- Salón comunal 
- Tienda de artesanías + talleres de artesanías

- Museo de sitio

- Puesto policial

- Plaza de Armas.

- Camal

- Cementerio

- Terminal terrestre

- Estadio

- Plaza de toros

- Pista de carreras

- Parque ecológico (Minpetel S.A., 2010, p. 43)

La necesidad de hacer inventarios en la comunidad de origen implicaba, como hemos dicho, una reposición en condiciones «iguales» o «mejores». Presentada como «moderna» por su apariencia, la infraestructura de la ciudad nueva fue creada ex nibilo. La infraestructura de la comunidad fue implementada, en la ciudad nueva, con nuevos bienes inmuebles (parque ecológico, un camal, un terminal terrestre) y nuevas instituciones (centro educativo, centro de salud). La ciudad nueva está rodeada, por un lado, por un cerro; por el otro, las paredes de las casas y los muros de contención dan la impresión de una ciudad hermética. De hecho, las dos entradas de la comunidad confirman la impresión de un espacio hermético.

La ciudad nueva presenta, también, particularidades que interrogan. No hablaremos aquí de la resistencia de las últimas familias que rechazaban el reasentamiento a la espera de indemnizaciones "más justas» y que, finalmente, fueron reasentadas en la ciudad nueva más de dos años (a inicios de 2017) después de que las primeras fueran trasladadas (fines de 2014).

Varios años después del reasentamiento, la relación estrecha entre la mina y la ciudad continúa principalmente por dos razones. La primera es que «el proyecto» (inicialmente a través de la empresa Xstrata) había acordado una serie de compensaciones a través de un contrato firmado, y todos los compromisos aún no habían sido respetados por la empresa encargada del proyecto. La segunda razón es que esta estableció, conjuntamente con la comunidad, que garantizaría a la ciudad nueva por varios ańos una suerte de servicio público, pero privado.

En Nueva Fuerabamba, el agua es gestionada y administrada por la empresa minera a las casi quinientas familias. La mina gestiona también los desechos caseros y urbanos. Los camiones de basura pasan varias veces a la semana para mantener la ciudad limpia. Las calles y las estructuras urbanas son, también, gestionadas por la entidad privada. Esta se ocupa de hacer reparar, a través de terceras empresas, las calles dañadas o los postes sin luz. Construida en menos de cuatro años, la ciudad nueva ya ha mostrado fallas. Algunas familias indican que sus puertas se despintaron muy rápido o que algunas no cierran bien debido a deformaciones del suelo. 
Otras perciben que las casas son frías. Algunas, dos años después de su llegada, empezaron a constatar grietas en algunas partes de sus casas.

Las transformaciones de la vida local y la gestión urbana por la empresa minera han levantado el tema estructural de la gestión administrativa y política de esta ciudad. Estas preguntas ya eran evocadas en el EIA:

En algunos casos, también se necesitará llevar a cabo discusiones y acuerdos con agencias del gobierno local y proveedores de servicio con respecto a la disponibilidad de servicios que normalmente son proporcionados por el gobierno, la disponibilidad de presupuesto para personal adicional y los costos recurrentes para instalaciones educativas y de salud, requisitos de capacitación para operaciones y mantenimiento de nueva infraestructura y otros aspectos similares. Las necesidades y expectativas de Chila y Choaquere relacionadas a su acceso a las instalaciones de Fuerabamba también tendrán que ser consideradas (Golder Associates, Vol. F, 2010, p. 4.65).

Años antes del reasentamiento, se preveía que los habitantes de las comunidades de acogida tendrían acceso a la infraestructura de la nueva ciudad vecina, «la cual será de mejor nivel que la de sus comunidades en la actualidad» (Vol. F, 2010, pp. 4.67-4.68); se preveía también que la educación y la salud de la ciudad nueva serían servicios apreciados por las comunidades vecinas en el futuro. Sería interesante estudiar estos aspectos en los próximos meses o años.

\section{De 4774 a 12 hectáreas. La reagrupación y la restricción de la vida rural}

Según la página web de la empresa Grańa y Montero $^{18}$, constructora de la ciudad nueva, la zona habitada de esta última corresponde a 12 hectáreas. Las habitaciones fueron juntadas en lotes, como es habitual en las zonas urbanas. Sin embargo, en este caso la concentración de la infraestructura en un espacio tan reducido no se asemeja a una pequeña ciudad, sino a un condominio dividido en trece partes. «Es de notar que, con la concentración del pueblo de Fuerabamba en una sola zona urbana, muchos recursos, particularmente la infraestructura de la comunidad, serán mucho más fácilmente accesibles a más personas» (Golder Associates, Vol. F, 2010, p. 4.66).

Estas trece partes corresponden a los trece caseríos de la antigua comunidad de Fuerabamba, donde las zonas habitadas se repartían en la totalidad del territorio de la comunidad; es decir 4774 hectáreas. El territorio compactado de la ciudad nueva responde a una visión modernizada y citadina de proximidad con los servicios "públicos» de base. Pero la «accesibilidad» a los servicios no debe ser confundida con la concentración. Este es ante todo el resultado de una imposibilidad de adquirir territorios cercanos con extensión suficiente para el reasentamiento.

${ }_{18}$ http://www.gym.com.pe/en/our-projects/project/project-ciudad-nueva-fuerabamba 
Ilustración 1. Nueva Fuerabamba. 13 de junio 2017

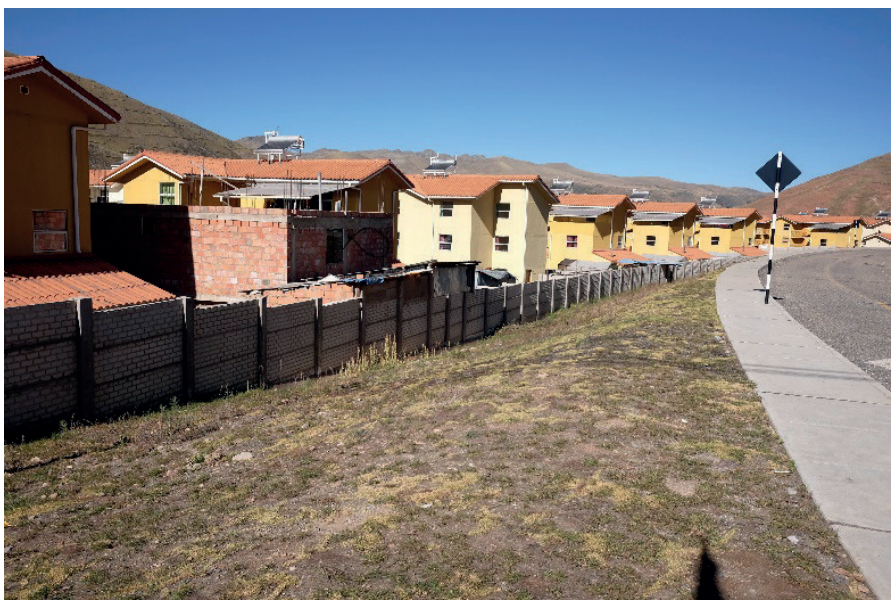

Fuente: Fotografía del autor.

Ilustración 2. Nueva Fuerabamba. 13 de junio de 2017

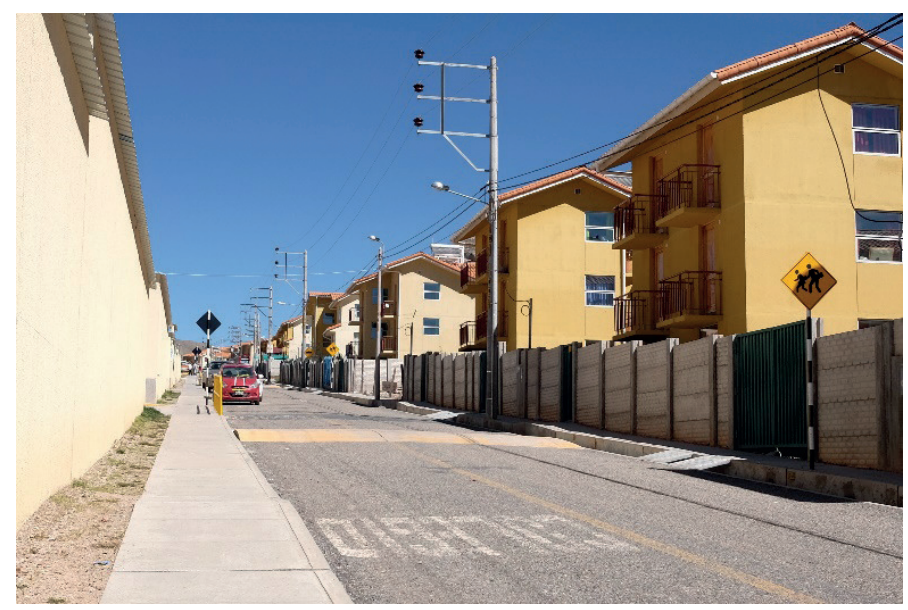

Fuente: Fotografía del autor.

Como ya mencionamos, las familias no querían alejarse del corazón del proyecto para poder aprovechar de las oportunidades económicas. La proximidad relacional con el proyecto les permitiría proponer sus microempresas como services localmente. En realidad, la falta de tierras disponibles obligó a que el territorio de la ciudad nueva esté formado como un archipiélago.

12 hectáreas, zona central de vivienda

350 hectáreas (incluye las 12 hectáreas de zona de vivienda). Es la extensión de la zona urbana de la ciudad nueva donde se encuentran las casas y los diferentes 
módulos de la infraestructura urbana (estadio, cementerio, pista de carrera de caballos, etc.).

11 hectáreas de terreno compradas en el sector Huayccoranra, cerca de Challhuahuacho. Debería recibir actividades económicas de negocios diversos. Está situado a 20 minutos de auto de Nueva Fuerabamba.

3800 hectáreas (Yavi-Yavi), terreno situado a más de tres horas de carretera de la ciudad nueva. Situado a más de 4500 m.s.n.m., Yavi-Yavi es un territorio de producción ganadera.

1200 hectáreas. «Debido a la ubicación de la zona urbana, la preferencia sólida es encontrar tierras agrícolas adecuadas para laymis dentro de la distancia de desplazamiento, es decir, dentro de los distritos de Challhuahuacho, Coyllurqui y/o Progreso» (Golder Associates, Vol. F, 2010, p. 4.63).

Y es verdad, en otros documentos, la extensión real o prevista de tierras de reemplazo se extiende a 3000 ha. Además de haber comprado otro terreno para fines agrícolas en el distrito de Haquira para la reposición de estas tierras, la empresa alquila grandes extensiones de terreno en varios sectores de la provincia para que cada caserío pueda seguir dedicándose a la agricultura. El terreno de Yavi-Yavi es muy alejado y es usado principalmente para ganadería y producción de productos derivados de la leche de vaca.

En su libro El desarraigo (1964), Bourdieu y Sayad evocan las dinámicas sociales y políticas generadas en las zonas rurales de Argelia en los años posteriores a la independencia (antes de 1962). Los pueblos rurales habían sido reagrupados en grandes campamentos vigilados por el ejército francés. Si bien nuestro caso no es comparable con el de Bourdieu y Sayad, la restricción territorial por una entidad administradora se aparenta a lo que los autores describen como la «reagrupación», es decir, la concentración práctica de la población para facilitar su gestión. Como indica la cita anterior, esta concentración territorial habría sido pensada para facilitar el acceso de las familias a los servicios urbanos, pero ante todo, esta concentración se debe a la falta de territorios consensuales, y en este caso podemos afirmar que, al fin y al cabo, la entidad administradora es la que terminó imponiendo lo que pudo obtener.

\section{Ciudad y ciudadanía}

En convenio con la comunidad, la empresa debe gestionar el manejo de la infraestructura y de los «servicios públicos» de la comunidad por algunos años después del reasentamiento. Habiendo sido arquitecto de la ciudad nueva, «el proyecto» gestiona el mantenimiento de los accesos a la comunidad, las calles, los desechos sólidos, los servicios de agua y luz, la infraestructura, pero también a través de convenios con la UGEL de Cotabambas y EsSalud, la educación y la salud de las familias. 
Desde hace varias décadas, las investigaciones sobre la «ciudad» como objeto de estudios se han renovado. Los nuevos trabajos, impulsados entre otros por la obra de Lefebvre (1967), fueron también el fruto de la urbanidad como fenómeno global con las olas de migración rural hacia las ciudades en los países del «tercer mundo». La migración y la construcción urbana por clases nuevas daban a conocer nuevas formas de construir socialmente la ciudad y de vivir en ella. Pero más allá de la infraestructura física, mostraba también nuevas formas de pensar y de vivir la ciudadanía. Así es como, apareciendo como «objeto», la ciudad empezaba a ser vista, también como un espacio de derecho que daba mayores posibilidades para la construcción de ciudadanías igualitarias. Frente al campo, la ciudad siempre ha representado el espacio de ciudadanía y de ejercicio de la política de Estado (Musset, 2002). Ambas dimensiones (ciudadanía y control) parecen intrínsecamente ligadas, pero son más o menos ejercidas según el relacionamiento institucional (político, histórico, social, etc.) de las entidades de gestión y de poder con la ciudadanía.

En este sentido, la transformación profunda de Fuerabamba desde la comunidad que era a la ciudad que es después del reasentamiento es una imagen muy singular. Explicamos por qué.

Hasta inicios de los años 2000, Fuerabamba era un territorio casi impenetrable, según los discursos locales. Sus habitantes eran temidos por las comunidades vecinas, ya que Fuerabamba era ante todo una comunidad de abigeos. En la década de 1970, según una señora que vivía en Fuerabamba en esa época, "todos» los hombres de la comunidad tenían orden de captura. La escasez de dinero en moneda y la poca cantidad de personas que contaba con DNI antes de los años 2000 hacía de Fuerabamba — según las narraciones locales_ un territorio al margen de la ciudadanía nacional. Pero en diez años, la situación se ha transformado profundamente. La llegada del proyecto minero trajo cambios sustanciales (campañas para obtención de DNI, fin del trueque, incremento del uso del dinero, capacitaciones técnicas, trabajo, etc.) que transformaron las dinámicas sociales y económicas de Fuerabamba. En los espacios urbanos marginalizados, Martuccelli indica que, en un contexto neoliberal, «[...] en los últimos lustros el sentimiento de participación social se ha afirmado más desde el consumo, y por la vía del mercado, que desde el imperio de los derechos» (Martuccelli, 2015, p. 278).

En nuestra opinión, el fenómeno se aplica también al contexto rural.

De cierta manera podemos decir que los habitantes de Fuerabamba han sido absorbidos en este proceso por una propuesta de ciudadanía totalmente singular, ya que antes y después del reasentamiento, las familias viven en un territorio administrado por "la mina», donde el Estado central se mantuvo relativamente alejado.

Además de ello, como parte del contrato de reasentamiento, la empresa (Xstrata, en aquella época) había acordado dar trabajo fijo por lo menos a una persona por 
familia. Los deseos y demandas de la comunidad llegaron a veces a sugerir mensualidades sin que sea necesario trabajar. En 2017, varias asambleas se dieron para encontrar acuerdos sobre el tema laboral. Una de las propuestas más seriamente estudiadas fue la de hacer trabajar a los habitantes en los territorios de su propia comunidad. Las personas no calificadas serían pagadas con mensualidades de 2000 soles y sus tareas serían de limpieza o mantenimiento de los espacios urbanos. Según su voluntad y su disponibilidad, otras trabajarían en los territorios productivos de la comunidad como en Yavi-Yavi, trabajando en el cuidado de ganado o en la gestión del territorio. Las personas diplomadas, los más jóvenes, tendrían mensualidades mayores (2800 soles) y trabajarían en labores técnicas, de asistencia o de ingeniería.

El trabajo es un argumento de aceptación temprana de la presencia minera, pero en el contexto del reasentamiento, el trabajo sigue siendo el eje fundamental que une la comunidad al proyecto "amarrados" por varios compromisos. Con las propuestas de trabajo, el proyecto ha generado una suerte de dependencia involuntaria. Bourdieu y Sayad (1964) sugieren que la «descampesinización» de la gente del campo argelino se debió al reagrupamiento de la población en espacios urbanizados. Esta disposición territorial y administrativa ha empujado paulatinamente a los campesinos a orientarse hacia trabajos urbanos y a olvidar y despreciar el campo, buscando nuevas oportunidades económicas en labores socialmente más valoradas. Poco a poco, las estructuras nuevas van imponiendo un ritmo urbano. Habiendo sido arquitecta de la ciudad nueva, la empresa debe administrar el espacio, las estructuras, los servicios y, al fin y al cabo, el bienestar de las familias, por lo menos hasta que se estabilice una forma sostenible de administración de la ciudad. Esto queda por verse en los próximos meses y años.

\section{Conclusión}

Hemos querido presentar aquí una mirada general sobre una situación de reasentamiento para el desarrollo de un proyecto minero. El reasentamiento es un proceso muy preciso (determinar personas afectadas o beneficiarias, clasificar los beneficiarios, valorar bienes, etc.) y a la vez muy amplio (gestionar tierras, compensaciones económicas, crear actividades laborales, gestionar infraestructura, agua, luz, etc.). Este conjunto de necesarias gestiones hace del reasentamiento un proceso político de gestión bastante complejo.

La creación de condiciones de gobierno - entendido como un sistema de ordenamiento y disciplina de personas - por la empresa minera ha sido el hilo director de esta propuesta. El ordenamiento social debe ser visto a la vez como un acto de poder político, como ya hemos subrayado, pero también como un proceso y un conjunto de formas sensibles de dominación (a través del tiempo, de la imposición 
de fechas limites o la imposición de sanciones posibles). Hemos tratado de mostrar cómo a través del tiempo —-mediante beneficios y promesas - las familias aceptan la convivencia y el reasentamiento. Esta aceptación debe ser entendida en gran parte como una apuesta hacia el futuro; de trabajo para los adultos y de educación para los jóvenes. Las promesas fueron escuchadas por las retóricas convincentes de la empresa y por dispositivos sutiles de presión para mantener el orden en la discreción. Así es que pasaron nueve años de convivencia. Pero las esperanzas previas al reasentamiento se volvieron, para muchos, desilusiones. Un sentimiento casi característico de los reasentamientos involuntarios.

$\mathrm{Al}$ parecer, el nuevo espacio urbano, por ahora, no alcanzó sus promesas. La utopía de un «futuro mejor» que se prometía a las familias tomó las formas de una distopía; las casas "térmicas» resultaron ser más frías de lo que los habitantes se imaginaron y, por partes, ciertas calles y casas ya presentaban importantes grietas solo dos años después de la instalación ${ }^{19}$.

Por otra parte, la disposición de las casas en Nueva Fuerabamba, la homogeneidad de la infraestructura propuesta y la concentración espacial son características de las «ciudades nuevas» propuestas en contextos de reasentamiento, ya sea por proyectos de desarrollo o por catástrofes naturales. Este tipo de arquitectura recuerda algunos conjuntos arquitectónicos cuyo fin es la optimización del espacio o la vigilancia. Los campamentos industriales a inicios del siglo XX o los company towns en la década de 1970 (ver Arcineaga Arce, 1985 y Bauch (1985) podrán servirnos, para una investigación futura, como ideales-tipos de comparación. Esto cristalizaría aún más la idea general de esta propuesta de observar los proyectos de «desarrollo» como emprendimientos potencial o simbólicamente violentos. Seguramente, los años que vienen aportarán — desde Nueva Fuerabamba — algunas respuestas a nuestras interrogaciones.

\section{REFERENCIAS}

Arcineaga Arce, R. S. (1985). Los mineros de la Southern. Allpanchis, 26, año XV, vol. XXII, 185-201. Cusco.

Absi, P. (2010). La parte ideal de la crisis: los mineros cooperativistas de Bolivia frente a la recesión. Cuadernos de Antropología, 31, 33-54.

Bauch E. (1985). Comunidad, conflicto y cambio social: el caso de la Southern Peru Copper Corporation. Allpanchis, Año XV, Vol XXII. Instituto de Pastoral Andina, 9-33.

Boccardi, F. G., S. Giovannini, M. Orellana y D. Rocchietti (2008). El sueño minero: un análisis de la narrativa utópica del desarrollo. Perspectivas de la comunicación, 1(1), 56-72.

\footnotetext{
19 Según las entrevistas realizadas en mayo y junio de 2017. Ver también URL: https://www.youtube. com/watch?v=Ony_KOql7lw
} 
Bourdieu P. y A. Sayad (1964). Le déracinement. La crise de l'agriculture traditionnelle en Algérie. París: Editions de Minuit.

CFI (2002). Manual para la preparación de un Plan de Acción de Reasentamiento. Promoción de inversiones privadas sostenibles. Washington.

Chateauraynaud, F. (2015). L’emprise comme expérience. SociologieS (online), Dossiers, Pragmatisme et Sciences Sociales: exploration, enquêtes, expérimentations.

Chateauraynaud, F. (2012). Des prises sur le futur Regard analytique sur l'activité visionnaire. En Bourg D., P. B. Joly y A. Kaufmann (dir.), Retour sur la société du risque - Actes du colloque de Cerisy (3-10 septembre, 2011).

Choquenaira, V. (2010). Avances de Las Bambas y desarrollo sostenible. Grupo de diálogo, minería y desarrollo sostenible. URL: www.grupodedialogo.org.pe/documentos/15\%20octubre\%202010\%20en\%20Grupo\%20Dialogo\%20Minero.pdf

Cingolani, P. (2012). L'attente du travail: sociologie du dispositif précaire. En P. Cingolani, Un travail sans limites? ERES Clinique du travail, pp. 123-141.

De Wind, A. (1985). De campesinos a mineros: el trasfondo de las huelgas en las minas del Perú. Allpanchis, año XV, XXII(26), 247-271.

Downing, T. (2002). Avoiding New Poverty: Mining-Induced Displacement and Resettlement, 58. IIED, WBCSD.

Downing, T. y C. García-Downing (2001). Plan B: What is going to happen to my people. Cultural Survival Quarterly, 25(2), 8-15.

Faure, A. (2008). Des normes sociales pour les déplacements de population causés par les grands barrages. France, $\mathrm{XX}^{\mathrm{e}}$ siècle. Revue de géographie alpine [En ligne], 96-1 | 2008, mis en ligne le 03 mars 2009.

Foucault, M. (2004). Cours au Collège de France. Sécurité, territoire, population (19771978). París: Le Seuil-Gallimard.

Foucault, M. (1975). Surveiller et punir. La naissance de la prison. París: Gallimard.

Golder Associates (2010). Estudio de impacto ambiental proyecto minero Las Bambas. Volumen F. Evaluación de Impactos Socioeconómicos. Lima: Golder Associates.

Golder Associates (2010). Estudio de impacto ambiental proyecto minero Las Bambas. Volumen A. Generalidades del Estudio de Impacto Ambiental. Lima: Golder Associates.

Hervé, B. (2013). De campesinos a microempresarios: transformaciones laborales y cambios sociales en una comunidad campesina del Perú. Iluminuras, 33, v. 14, 33, 50-74, jul. /dez. 2013. Porto Alegre.

Hervé, B. (2012). En attendant d'être réinstallés: discours et conflit autor des enjeux du déplacement d'une communauté paysanne au Pérou, 71-88. Autrepart, 64, variations, IRD, Les presses sciencesPo, Paris.

Independent Advisory Group (IAG) (2010). Informe Grupo Asesor Independiente, 2008marzo 2010.

Lefebvre, H. (1967). Le droit à la ville. In: l'Homme et la société, 6, 1967, 29-35.

Margier, A. (2016). Cohabiter l'espace public. Conflits d'appropriation et rapports de pouvoir à Montréal et Paris. Rennes: PUR. 
Martuccelli, D. (2015). Lima y sus arenas. Poderes sociales y jerarquías culturales. Lima: Cauces.

Mejorada Chauca, M. (2003). Las servidumbres y la explotación de recursos naturales. Ius et veritas, XIII(27), 12-21.

MEM (2011). Resolución Directoral 073-2011-MEWAAM. Lima: Ministerio de Energía y Minas, 7 de marzo.

Minpetel (2010). Estudio de Impacto Ambiental Semidetallado para la construcción de la Urbanización Nueva Fuerabamba: Lima.

Musset, A. (2002). Villes nomades du nouveau monde. París: Editions de l'école des Hautes Études en Sciences Sociales.

ProDiálogo (2006). Fortalecimiento del diálogo para el relacionamiento constructivo en el entorno del proyecto minero Las Bambas. Lima.

ProInversión (2005). Las Bambas. Un modelo de desarrollo sostenible. Lima: Proinversión.

Puerta Silva, C. (2009). Les indiens wayuu et le projet minier du Cerrejón en Colombie: Stratégies et politiques de reconnaissance et d'identité. Tesis de doctorado. París: EHESS.

Sebenius, J. K., Eiran, E., Feinberg, K. R., Cernea, M. y McGovern, F. (2005). Compensation schemes and dispute resolution mechanisms: Beyond the obvious. Negotiation Journal, 21(2), 231-244.

Sencébé, Y. (2004). Être ici, être d`ici. Formes d'appartenance dans le Diois (Drôme). Ethnologie française, 34(1), 23-29.

Szablowski, D. (2002). Mining, displacement and the World Bank: A case analysis of compania minera Antamina's operations in Peru. Journal of Business Ethics, 39(3), 247-273.

Vidal, L. y Musset, A. (dirs.) (2015). Les territoires de l'attente. Migrations et mobilités dans les Amériques (XIXe-XXI siècle). Rennes: PUR, Institut des Amériques. 